\title{
Immunopathology of necrotising scleritis
}

\author{
Yoshihiko Usui, ${ }^{1,2}$ Jignesh Parikh, ${ }^{1}$ Hiroshi Goto, ${ }^{2}$ Narsing A Rao ${ }^{1,2}$
}

${ }^{1}$ A Ray Irvine Ocular Pathology Laboratory, the Doheny Eye Institute, and the Department of Ophthalmology, Keck School of Medicine of the University of Southern California, Los Angeles, CA, USA; ${ }^{2}$ Department of Ophthalmology, Tokyo Medical University, Tokyo, Japan

Correspondence to: Yoshihiko Usui, MD, Department of Ophthalmology, Tokyo Medical University, 6-7-1 Nishishinjuku, Shinjuku-ku, Tokyo 160-0023, Japan; usuyoshi@ aol.com

Accepted 2 December 2007

\section{ABSTRACT}

Aim: To detect the immunohistopathology of necrotising scleritis.

Methods: Immunohistochemical staining was performed on two groups of enucleated eyes with necrotising scleritis (systemic autoimmune disease and idiopathic scleritis). Deparaffinised sections were stained with CD3, CD20, CD68, CD8, CD4 and dendritic reticulum cells (DRC).

Results: Within the autoimmune group, about $43 \%$ of inflammatory cells stained positive with CD20, 35\% with CD68, 17\% with CD3, 8\% with CD8, 4\% with DRC and less than $1 \%$ with CD4. Within the idiopathic group of eyes, about $43 \%$ of cells stained positive for CD68, 23\% for CD3, 17\% for CD20, 7\% for CD8, 1\% for DRC and less than $1 \%$ for CD4.

Conclusions: The infiltrate within the group of eyes with systemic autoimmune disease suggests that the inflammation may be driven by B cells. However, the large numbers of CD68 cells found in both groups of eyes indicate that macrophages could play a role in the necrotising process.

Scleritis is a painful inflammatory eye disease with diverse aetiologies and obscure pathogenesis. The disease usually affects adults, mean age of 52 years, ${ }^{1}$ and is associated with systemic disease in $50 \%$ of patients. ${ }^{2}$ Within its clinical classification, necrotising scleritis is the most severe and destructive form of the disease. As we previously reported, necrotising scleritis is not a single histopathological entity but is made up of four distinct patterns of inflammatory infiltration, reflecting diverse immunopathogenetic mechanisms. ${ }^{2}$ The patterns were necrotising zonal granulomatous inflammation, diffuse non-granulomatous chronic inflammation, mixed pattern of acute purulent inflammation mixed with granulomatous inflammation and sarcoidal pattern. ${ }^{2}$ The zonal granulomatous inflammation was typically associated with systemic autoimmune diseases such as rheumatoid arthritis or collagen vascular disease, whereas diffuse non-granulomatous inflammation has no recognisable cause or association with systemic disorders. ${ }^{2}$

Immunohistochemical studies of scleritis have been primarily confined to tissues obtained by episcleral and conjunctival biopsies because of the high rate of complications associated with scleral biopsies. Similarly, the initiation of treatment for these conditions can resolve symptoms and contribute much needed tissue for study. Assessment of histopathological events within the sclera (the site of ongoing necrosis) is important for a greater understanding of the disease process and more effective therapeutic intervention. Thus, we evaluated two groups of enucleated eyes with necrotising scleritis to characterise the composition of the scleral cellular infiltrate using immunohistochemical methods.

\section{MATERIALS AND METHODS}

Using the histopathological grouping proposed by Rao et $a l^{2}$ we selected three eyes from each of two groups: (1) eyes with necrotising zonal scleral inflammations associated with rheumatoid arthritis (autoimmune diseases); (2) eyes with diffuse nongranulomatous scleral inflammations without associated systemic disorders (the idiopathic group). All six enucleated eyes were from patients who had complications resulting in blindness, pain, or both, based on the clinical data. All six eyes had histological features of primary scleral inflammation associated with necrosis. Paraffin blocks of the eye samples were re-cut for immunohistochemical study using monoclonal mouse anti-human CD3, CD4, CD8, CD20, CD68 and DRC antibodies ${ }^{3}$ (1:50, Dako, Carpinteria, CA, USA). The antibodies included anti-CD3 for pan T lymphocytes, CD4 for helper $\mathrm{T}$ lymphocytes, CD8 for cytotoxic-suppressor T lymphocytes, CD20 for B lymphocytes, CD68 for macrophages and DRC for dendritic reticulum cells. The immunostaining was performed by hand. Briefly, the sections were deparaffinised and antigens were retrieved by covering sections with $10 \mathrm{M}$ sodium citrate buffer and heating (20 seconds) in a microwave. The sections were incubated with one of the above antibodies overnight and then with the secondary antibody, goat anti-mouse IgG biotin (1:100, Dako), for 2 hours. The signal was enhanced with the avidinbiotin complex kit; (ABC kit; Vector Laboratories, Burlingame, CA, USA) before visualisation with 3amino-9-ethylcarbazole (AEC, Dako). Five haematoxylin-eosin-stained sections, one periodic acidSchiff-stained section and one each of the immunomarker-stained sections from each sample were observed using the light microscope. Lymphoid tissue sections were used as positive controls. Using light microscopy, we examined three high-power fields with scleral inflammation. Within those fields the total number of cells and the number of immunopositive cells for each marker were counted. The percentage of positive cells with mean, standard deviation, and the $p$ values for each immunohistochemical marker were calculated. The $p$ value for each immunohistochemical marker was calculated by the Student t test.

\section{RESULTS}

The clinical data are summarised in table 1 . The mean patient age (SD) is 73.3 (3.5) years (range 7077 years) for the autoimmune-associated group and 57.7 (8.3) years (range 51-67 years) in the idiopathic group $(p=0.04)$. Two female eyes and one male eye represented the autoimmune group while all three patients in the idiopathic group are online under the BMJ Journals unlocked scheme, see http:// bjo.bmj.com/info/unlocked.dtl 
Table 1 Clinical information and demographics

\begin{tabular}{lll}
\hline Histopathological findings & Demographics & Clinical information \\
\hline $\begin{array}{l}\text { (A) Autoimmune-mediated group } \\
\text { Mononuclear cell infiltration zonal granulomatous } \\
\text { inflammation around necrotic sclera }\end{array}$ & $\begin{array}{l}\text { 70-year-old male } \\
\text { Mononuclear inflammation zonal granulomatous } \\
\text { inflammation surrounding focal areas of collagen necrosis }\end{array}$ & $\begin{array}{l}\text { Left eye with pain and marked } \\
\text { inflammation } \\
\text { History of rheumatoid arthritis }\end{array}$ \\
$\begin{array}{l}\text { Necrosis and zonal granulomatous inflammation } \\
\text { Right eye with right-sided facial pain and } \\
\text { (B) Idiopathic group }\end{array}$ & $\begin{array}{l}\text { eye inflammation } \\
\text { (+) Rheumatoid factor }\end{array}$ \\
$\begin{array}{l}\text { Foci of scleral necrosis } \\
\text { No zonal pattern }\end{array}$ & $\begin{array}{l}\text { (+) ANA } \\
\text { Lymphocytes and plasma cells }\end{array}$ & $\begin{array}{l}\text { Right eye with pain } \\
\text { History of severe rheumatoid arthritis }\end{array}$ \\
$\begin{array}{l}\text { Foci of scleral necrosis } \\
\text { Plasma cells, lymphocytes, xanthoma-like cells, } \\
\text { macrophages }\end{array}$ & 51-year-old male \\
$\begin{array}{l}\text { Focal scleral necrosis } \\
\begin{array}{l}\text { Polymorphonuclear leucocytes, lymphocytes, plasma } \\
\text { cells }\end{array}\end{array}$ & $\begin{array}{l}\text { Right eye with chronic retinal detachment } \\
\text { and necrotising scleritis }\end{array}$ \\
\hline
\end{tabular}

males. In both groups, the involved eyes were two right eyes and one left eye. Three patients in the autoimmune group had a history of rheumatoid arthritis. The eyes in the autoimmuneassociated group revealed a zonal granulomatous inflammation with a central necrotic sclera surrounded by an inner zone of polymorphonuclear leucocytes, histiocytes, and giant cells and an outer zone of lymphocytes and plasma cells. The eyes in the idiopathic group exhibited a diffuse, non-granulomatous, chronic infiltration and necrotic sclera. The composition of the immunoreactive cellular infiltrate is summarised in table 2 . The scleral cellular infiltrate found in the eyes of the autoimmune group consisted primarily of B lymphocytes (CD20) and macrophages (CD68). In the idiopathic group, the cellular infiltrate was primarily composed of macrophages (CD68) and, to a lesser extent, $\mathrm{T}$ lymphocytes (CD3). Infiltrate that stained positive with suppressor $\mathrm{T}$ lymphocytes (CD8) was minimal; infiltrate that stained positive with helper T lymphocytes (CD4) and dendritic reticulum cells (DRC) was even more negligible.

\section{DISCUSSION}

It has been proposed that autoimmune scleritis may be associated with immune complex-mediated immunopathogenesis, whereas idiopathic scleritis may be associated with a delayed hypersensitivity reaction. ${ }^{4}$ However, few studies have actually analysed the composition of the inflammatory cell infiltrate in such cases. Accordingly, we examined the composition of the inflammatory cellular infiltrate in necrotising scleritis to delineate the immune reactive cells involved in the scleral inflammation. Similar to previous studies, ${ }^{56}$ our investigation also found that the inflammatory cellular infiltrate in necrotising scleritis is primarily composed of lymphocytes and macrophages. However, while previous studies have noted infiltrate containing a predominance of $\mathrm{T}$ lymphocytes and helper $\mathrm{T}$ cells, the present study revealed a preponderance of $\mathrm{B}$ lymphocytes among patients with autoimmune uveitis and macrophages within the infiltrate of those with both autoimmune and idiopathic scleritis (table 2).

When compared with that of the idiopathic group, the eye infiltrate of the autoimmune-associated group is primarily composed of CD20 positive cells along with plasma cells (fig 1), suggesting that autoimmune necrotising scleritis could be mediated by the B cell process. However, large numbers of CD68 cells in both groups (fig 2) may indicate that macrophages could play a role in the necrotising process noted in both groups of eyes.

The $\mathrm{p}$ values for CD20 and DRC show only borderline statistical significance; the ability to detect statistically significant differences is restricted by the small sample size. With $90 \%$ power and $\alpha=0.05$, a minimum of six samples in each group would be desirable to detect statistical significance. Therefore, further studies using larger numbers of enucleated eyes would be required to firmly establish the statistical significance of the cellular infiltration in both forms of the disease.

In summary, necrotising scleritis is a potential threat, not just to eyesight but to life as well. Early treatment is fundamental for the control of intraocular inflammation and for the prevention of systemic complications. ${ }^{1}$ Consequently, the elucidation of precise immune mechanisms involved in necrotising scleritis can potentially lead to curative treatments and to early intervention of this disease. Such intervention can be both sight-preserving and life-saving.

Table 2 Immunoreactive cell infiltration (percentage (SD)) in six enucleated eyes with necrotising scleritis

\begin{tabular}{lrrl}
\hline Immunomarkers & Autoimmune & Idiopathic & p Value \\
\hline CD20 & $43(15)$ & $17(10)$ & 0.06 \\
CD3 & $17(6)$ & $23(10)$ & 0.42 \\
CD4 & $<1$ & $<1$ & - \\
CD8 & $8(3)$ & $7(3)$ & 0.70 \\
CD68 & $35(15)$ & $43(6)$ & 0.43 \\
DRC & $4(2)$ & $1(0)$ & 0.06 \\
\hline
\end{tabular}



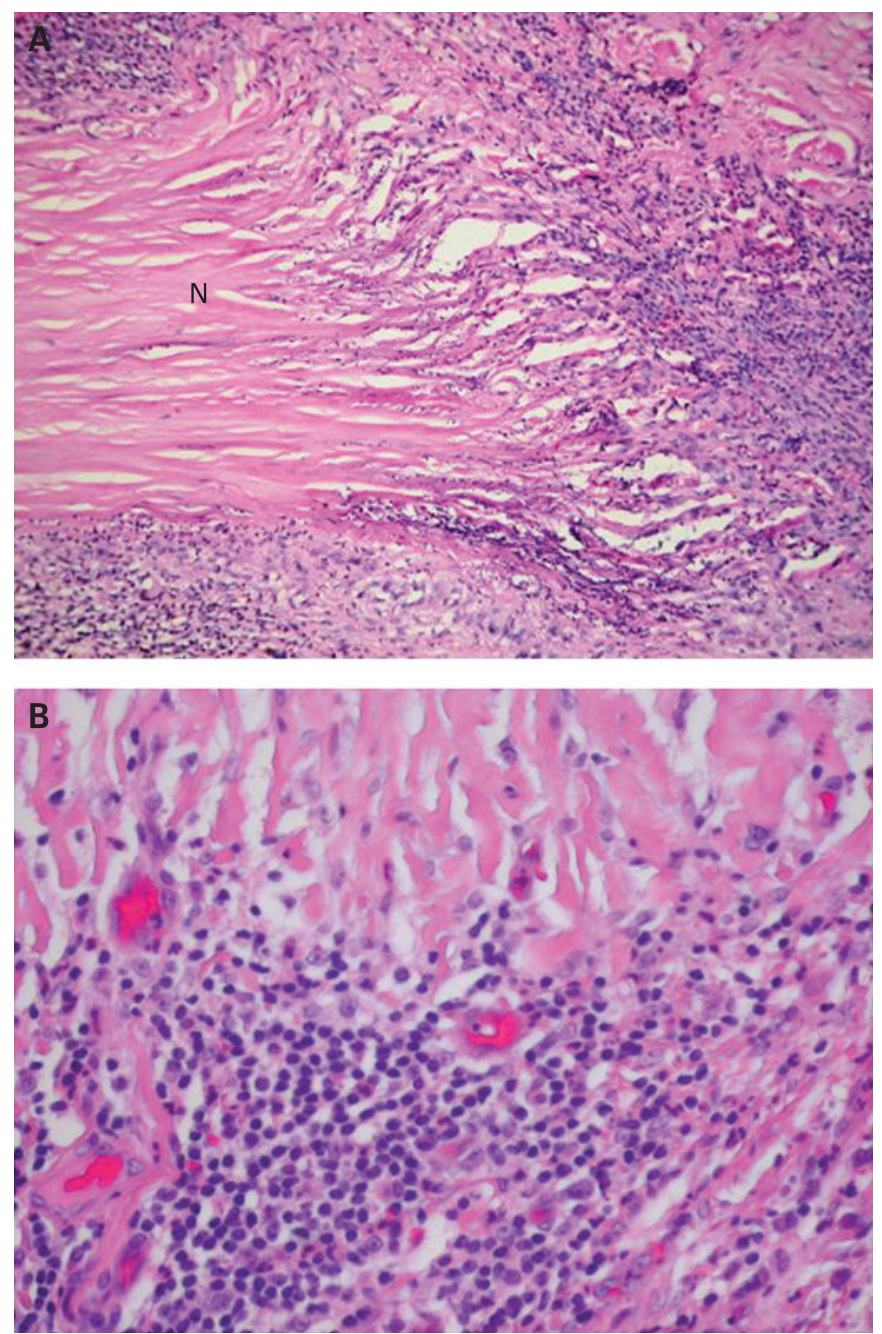

Figure 1 (A) Zonal necrotising granulomatous inflammation of the sclera in a patient with a clinical diagnosis of rheumatoid arthritis. N: necrotic scleral tissue (original magnification $\times 25$ ). (B) Scleritis in a patient with no evidence of associated disease. There is a diffuse involvement of the sclera with infiltration of inflammatory cells (haematoxylin and eosin, original magnification $\times 80$ ).

Acknowledgements: The authors thank Laurie LaBree, MS, Department of Preventive Medicine, Statistical Consultation and Research Center, University of Southern California for her assistance.

Funding: This study was supported in part by grant no EY03040 from the National Institutes of Health, an unrestricted grant from Research to Prevent Blindness Inc, New York, and grant-in-aid 19791294 for Scientific Research from the Japan Society for the Promotion of Science.

Competing interests: None declared.
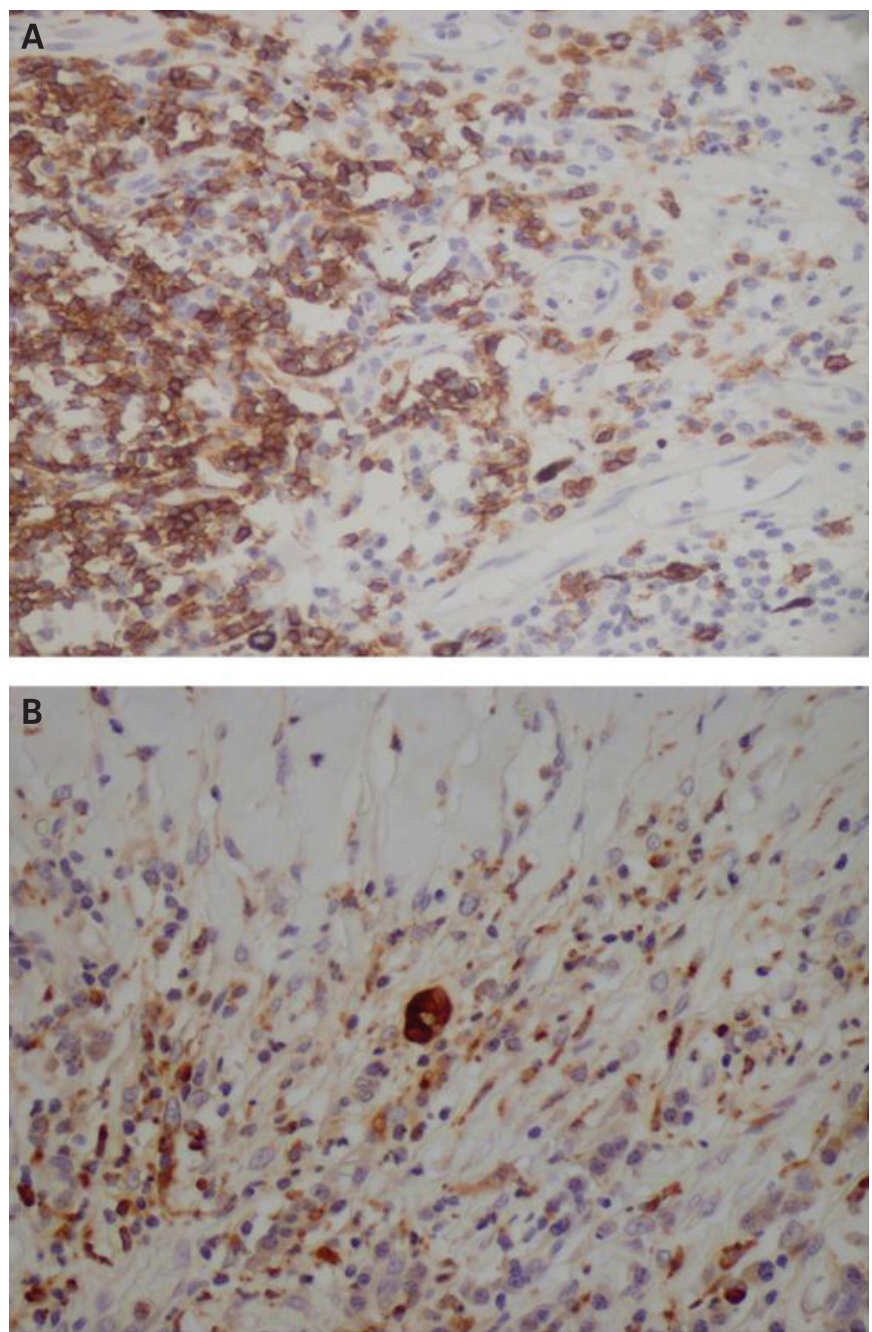

Figure 2 (A) Infiltration of CD20-positive cells in the autoimmune group (original magnification $\times 100$ ). (B) Large numbers of CD68 cells in the idiopathic necrotising scleritis groups (original magnification $\times 80$ ).

\section{REFERENCES}

1. Legmann A, Foster CS. Noninfectious necrotizing scleritis. Int Ophthalmol Clin 1996;36:73-80.

2. Rao NA, Marak GE, Hidayat AA. Necrotizing scleritis. A clinico-pathologic study of 41 cases. Ophthalmology 1985;92:1542-9.

3. Raymond I, Al Saati T, Tkaczuk J, et al. CNA.42, a new monoclonal antibody directed against a fixative-resistant antigen of the follicular dendritic reticulam cells. Am J Pathol 1997:151:1577-85.

4. Riono WP, Hidayat AA, Rao NA. Scleritis: a clinicopathologic study of 55 cases Ophthalmology 1999;106:1328-33.

5. Fong LP, Sainz de la Maza M, Rice BA, et al. Immunopathology of scleritis. Ophthalmology 1991;98:472-9.

6. Bernauer W, Watson PG, Daicker B, et al. Cells perpetuating the inflammatory response in scleritis. Br J Ophthalmol 1994:78:381-5. 